\title{
Lactobacillus rhamnosus/Lactobacillus reuteri Probiotic Supplement
}

National Cancer Institute

\section{Source}

National Cancer Institute. Lactobacillus rhamnosus/Lactobacillus reuteri Probiotic

Supplement. NCI Thesaurus. Code C150402.

A probiotic supplement containing the bacteria Lactobacillus (L.) rhamnosus and L. reuteri, with potential restorative and protective activities. Upon oral administration of the L. rhamnosus and L. reuteri probiotic supplement, the bacteria may restore and provide balance to the microbiota in the breast tissue. This may reduce or prevent inflammation, and may protect against the invasion of harmful bacteria and infection in the breast. In addition, the bacteria may restore the natural balance of the vaginal flora. This may prevent the invasion of harmful bacteria and yeast, and may prevent bacterial and yeast infections. This supplement may also relieve symptoms such as vaginal itching, odor and discharge, and may improve vaginal discomfort. 